\title{
ROOT CAUSE FAILURE ANALYSIS OF BLANKING DEVICE OF STRAINER HOUSING USED IN STEAM TURBINE
}

\author{
Sandeep Kumar ${ }^{1}$, Alok Singh ${ }^{2}, \mathrm{C}$ SasiKumar ${ }^{3}$ \\ ${ }^{I}$ M.Tech Maintenance Engineering \& Management, ${ }^{2}$ Faculty, Department of Mechanical Engineering, M.A.N.I.T. Bhopal \\ India, ${ }^{3}$ Faculty, Department of Material Science \& Metallurgical Engineering, M.A.N.I.T. Bhopal India \\ samdeemanit@gmail.com,er_aloksingh@rediffmail.com,csasimv@yahoo.com
}

\begin{abstract}
Failure analysis is the process of identifying the causes and factors leading to undesired loss of functionality. Failure investigators use several kinds of notions to explain this loss. An important one is that of a root cause failure analysis. This paper presents a root cause failure analysis and methodology followed in post weld failure investigation of blanking device which fails during post weld heat treatment. After performing fault tree analysis it is found that the failure may happen due to material defect or generation of residual stress during post weld heat treatment.
\end{abstract}

Keywords-Residual stress, Blanking device,Gr: 21CrMoNiV4-7, ANSYS, FTA $* * *$

\section{INTRODUCTION}

Failure analysis is the process of collecting and analyzing data to determine the cause of a failure. It is a vital tool used in the development of new products and for the improvement of existing products. Several engineering disciplines and activities deal with product or component failure, such as risk assessment, safety science, reliability engineering and failure analysis. Avoiding failure is an even more important aim of engineering design. In many of the cases failure occurs at the manufacturing stage which interrupts the continuity of production, causes loss of asset etc. Blanking Device of Strainer Housing used in Steam Turbine fails during post weld heat treatment. The cost of blanking device is 60 lakhs at Bharat Heavy Electricals Limited Bhopal after failure the material of blanking device goes to scrap so to avoid such future failure, failure analysis of failed component is needed. Precision Engineering Components, Govindpura Bhopal manufactures the blanking device. While welding it is found that the blanking device fails during post weld stress relieving with noise and crack after 600 seconds of manual arc welding. Blanking device used as emergency control valve at high temperature $\left(450^{\circ} \mathrm{C}-550^{\circ} \mathrm{C}\right)$ and high pressure $(50-60$ mega Pascal) conditions in strainer housing.

Strainer housing is a part of steam turbine is normally mounted preceding a pump to prevent large particles from entering the pump impeller.It is assembly of blanking plate and drain stub joined by arc welding.

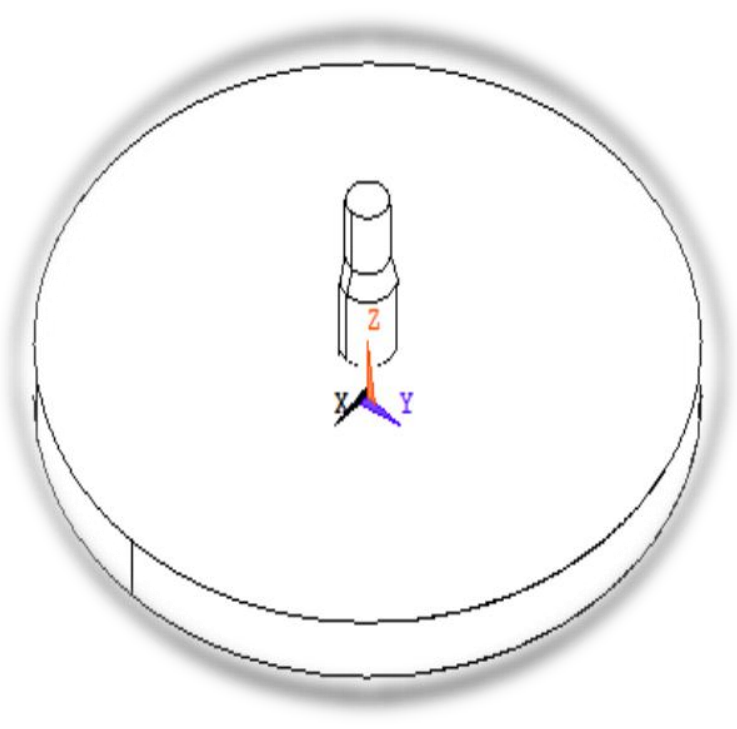

(Blanking Device)

The aim of this paper is to draw fault tree analysis diagram of failure and proposed a methodology to investigate the failure. The paper is organized as follows. In Section 2 we present case history of failure, how it happens and all the technical information. Section 3 provides conceptual approaches towards root cause failure analysis, its technique fault tree analysis and FTA diagram. Section 4 deals with the proposed methodology to investigate the failure. InSection 5, we combine our findings of Sections 3 and 4. Finally, we drawour conclusions in Section 6. 


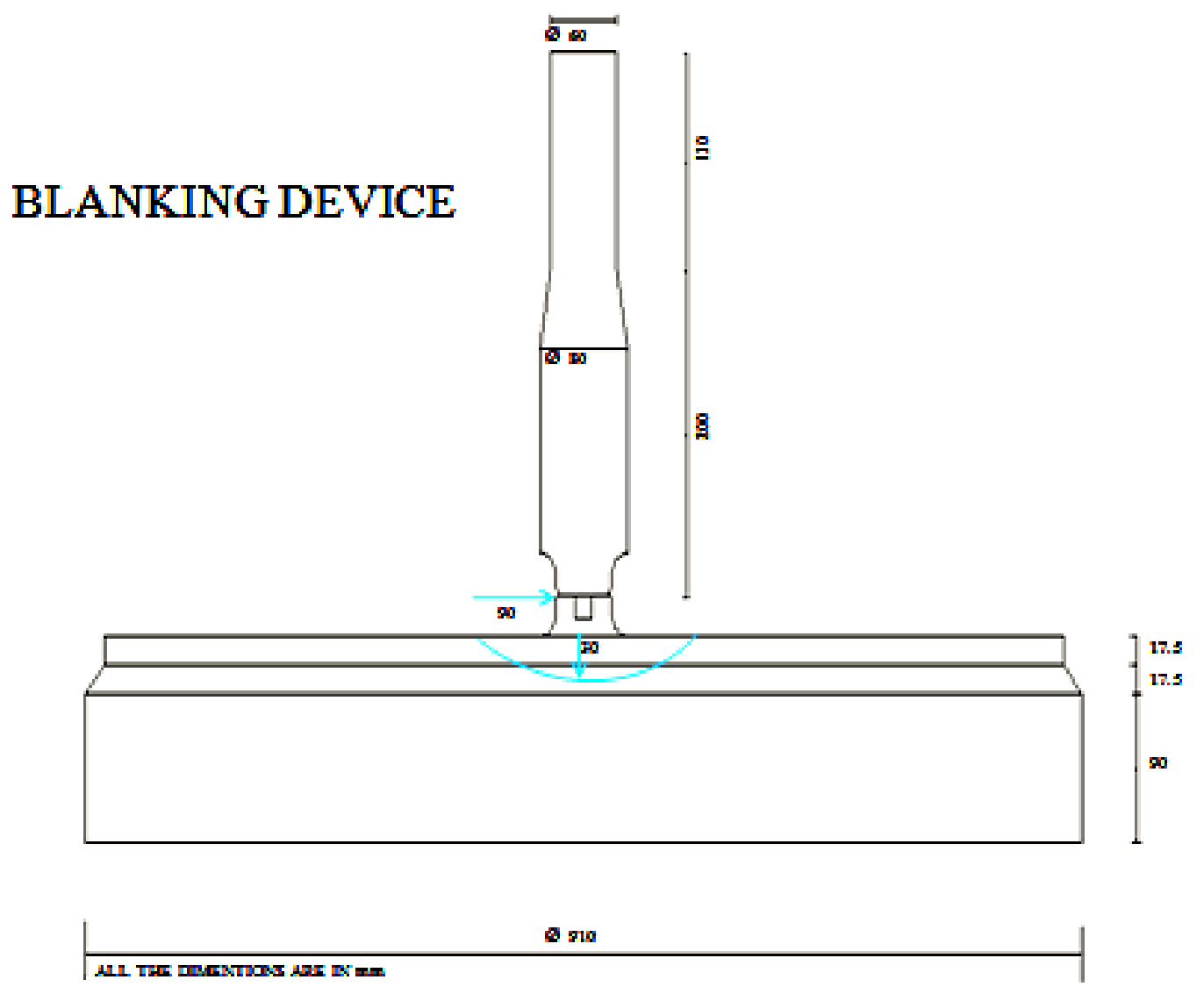

\section{CASE HISTORY}

Blanking plate is made of chromium alloy steel (Gr: 21CrMoNiV4-7) and drain stub is also made of chromium alloy steel (Gr: 11CrMo9-10). The welding electrode also has similar chemical composition. The chemical composition and mechanical properties of the blanking plate, drain stub and welding electrode is given as:

\section{Chemical composition (wt \%):}

\begin{tabular}{|l|l|l|l|}
\hline Element & $\begin{array}{l}\text { Blanking } \\
\text { Device }\end{array}$ & Drain Stub & $\begin{array}{l}\text { Welding } \\
\text { Electrode }\end{array}$ \\
\hline $\mathrm{C}$ & $0.17-0.25$ & $0.08-0.15$ & $0.10-0.12$ \\
\hline $\mathrm{P}$ & 0.020 & 0.025 & 0.025 \\
\hline $\mathrm{Mo}$ & $0.65-0.80$ & $0.90-1.10$ & $0.90-1.20$ \\
\hline $\mathrm{Al}$ & 0.015 & - & - \\
\hline $\mathrm{Si}$ & $0.15-0.35$ & 0.50 & $0.10-0.40$ \\
\hline $\mathrm{S}$ & 0.020 & 0.015 & 0.020 \\
\hline $\mathrm{Ni}$ & $0.50-0.80$ & - & 0.10 \\
\hline $\mathrm{Mn}$ & $0.35-0.85$ & $0.40-0.80$ & $0.40-0.90$ \\
\hline $\mathrm{Cr}$ & $0.90-1.20$ & $2.00-2.50$ & $2.00-2.50$ \\
\hline $\mathrm{V}$ & $0.25-0.35$ & - & 0.03 \\
\hline
\end{tabular}

Mechanical Properties:

\begin{tabular}{|l|l|l|l|}
\hline & $\begin{array}{l}\text { Blanking } \\
\text { Device }\end{array}$ & Drain Stub & $\begin{array}{l}\text { Welding } \\
\text { Electrode }\end{array}$ \\
\hline $\begin{array}{l}\text { Yield } \\
\text { Stress }\end{array}$ & $600 \mathrm{~N} / \mathrm{m} 2$ & $315 \mathrm{~N} / \mathrm{m} 2$ & $658 \mathrm{~N} / \mathrm{m} 2$ \\
\hline $\begin{array}{l}\text { Tensile } \\
\text { Stress }\end{array}$ & $700 \mathrm{~N} / \mathrm{m} 2$ & $520 \mathrm{~N} / \mathrm{m} 2$ & $\begin{array}{l}775 \quad \text { UT } \\
\text { N/m2 }\end{array}$ \\
\hline $\begin{array}{l}\text { Impact } \\
\text { Energy }\end{array}$ & $24 \mathrm{~J}$ & $60 \mathrm{~J}$ & $159 \mathrm{~J}$ \\
\hline Hardness & $215 \mathrm{HB} 30$ & $130 \mathrm{HB} 30$ & - \\
\hline
\end{tabular}

Blanking plate is a chromium alloy steel disc of $910 \mathrm{~mm}$ diameter and a height of $125 \mathrm{~mm}$. Drain stub is a chromium alloy steel shaft of $80 \mathrm{~mm}$ diameter which is tapered to $60 \mathrm{~mm}$ diameter at upper part.

Frequency of failure is found two out of eight and $100 \%$ Ultrasonic testing has been performed before welding. The welding environment was at room temperature and open atmosphere. For welding bottom circular part of drain stub fits on hole of blanking plate. Before welding blanking plate is preheated upto $200^{\circ} \mathrm{C}$ by gas cutting torch. Then manual arc welding started and finished while cooling the visible cracks 
appeared on the surface of blanking plate with noise and assembly fails. The failure happens $90 \mathrm{~mm}$ far and $30 \mathrm{~mm}$ below the welding zone.

- $\quad$ NDT before weld: Welding current: 250amp

- Welding voltage: 25 Volt

- Weld speed: $5 \mathrm{~mm} / \mathrm{second}$

- Weld time: 1200 seconds

- Welding Electrode: E-9018

- Dia:5.0mm, Length:450mm

After welding the blanking device isleft at open atmosphere for cooling and stress relieving. It is found that after some time at heat affected zone the cracks are developing. The number of cracks is increasing and weld fails with cracking sound.

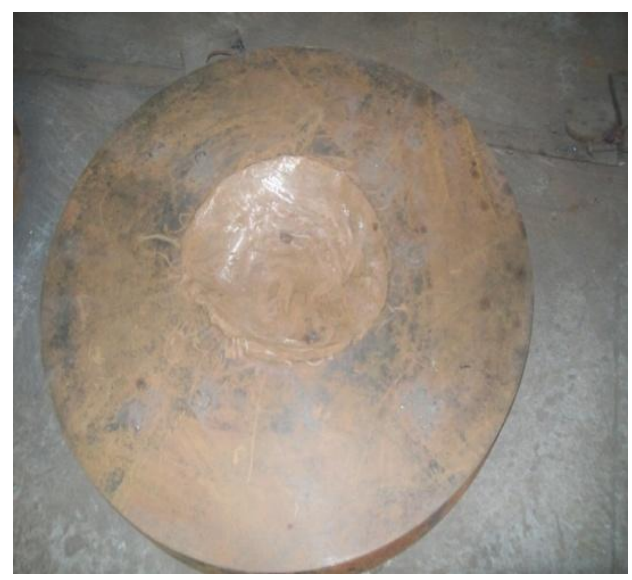

(Failed Blanking Plate)

- Number of cracks: 120-130

- Direction of cracks: Radically

- Length of cracks: $10 \mathrm{~mm}-25 \mathrm{~mm}$, Width of cracks: $3 \mathrm{~mm}-7 \mathrm{~mm}$, Distance of cracks from centre: $88 \mathrm{~mm}$ $96 \mathrm{~mm}$

\section{FAULT TREE ANSLYSIS}

Root Cause Failure Analysis is aInvestigative techniques applied to the determination of factorsleading to an initiating or originalfailure. The basic necessary actions in root cause failure analysis are [3]:

(a) Preserving failure data-Strategize to collect pertinent failure data to ensure that necessary facts are available for the analysis.

(b) Ordering the analysis-The best Root cause failure analysts are those that are unbiased and can facilitate the expertise of the teammembers.

(c) Analyzing the data-Analysis methods should represent a disciplined approach to graphically depict the sequence ofevents and errors that lead to failure. This sequence of errors should be validated with factual data. Root causes should include physical, human and organizational causes.

(d)Communicating the findings and recommendationsMake sure that approved recommendations are given a high priority to those that distributeresources to accomplish work. Also make sure that others in your company that can learn from your analysisare on the report distribution list.

\section{(e) Tracking the results.}

In the failure analysis of blanking device these actions have been applied and know the failure reason the fault tree analysis also performed.

Fault tree analysis is a graphical representation of the major faults or critical failures associatedwith a product, the causes for the faults, and potential countermeasures. The tool helps identifyareas of concern for new product design or for improvement of existing products. It also helpsidentify corrective actions to correct or mitigate problems.

A fault tree then constructed downward by relating the sequences of events, which individually or in a combination, could lead to the top level Event/Failure. Ishikawa's cause and effect diagram (fish bone diagram) or other techniques may be used for that. Fault tree analysis may also rely on solid theories such as Boolean logic Theory (which reduces the fault tree structure into the combinations of events leading to failure of the system, generally referred as minimal cut sets) and probability theory.

For above failure analysis the Boolean logic technique and brainstorming has been applied.

In the above problem the main concern is to find the post weld failure reason. So in fault tree analysis the top box is titled post weld failure of blanking device. The fault reasons have been identified through Brainstorming and came out as improper operation, welding parameters,post weld stress relievingand material imperfection.

1. Improper Operation: The welding had performed by well skilled operators who has sufficient experience to doing so. Now investigation goes in two directions, Manual errors or equipment problem or both.

(a) Manual errors: Firstly operator's actions had been examined and it is found that they had made no mistake and followed set pattern designed by senior engineer as they had used in previous successful welding.

(b) Equipment problem: For manual arc welding proper and good condition equipments had selected. In the investigation the condition of equipments have been checked and found 
according to specification, means there is no problem in any of equipments used in welding.

2. Welding Parameters: Now the investigation goes in the direction of selection of welding parameters such as welding electrode, welding current and voltage, welding speed and pre heating temperature.

(a) Welding Electrode: Selection of welding electrode depends on followingcharacteristics [4]-

- $\quad$ Specific composition of the deposited weld metal.

- Specific mechanical properties of the deposited weld metal.

- Rate of metal deposition.

From above tables it has found that the chemical composition and mechanical properties of the metal and welding electrode are almost similar. So welding electrode used in welding was found correct. The electrode is E-9018 which has similar chemical composition and mechanical properties as blanking device.

(b) Welding Current and Voltage: In arc welding, the voltage is directly related to the length of the arc, and the current is related to the amount of heat input. Constant current powersupplies are most often used for manual welding processes. The welding current and voltage selection has found ok but as the primary failure reason is residual stress generation so welding current and voltage will cross check in investigation. (c) Welding Speed: Similarly the welding speed used in welding $5 \mathrm{~mm} / \mathrm{second}$ but it will comes under doubt that it is ok or not. So it will cross check in investigation.

(d) Pre Heating Temperature: The blanking plate is pre heated before welding up to $200^{\circ} \mathrm{C}$ by gas cutting torch. But the welding fails so it will cross check in investigation that it is ok or not.

3. Material imperfection: Now investigation goes in the direction of material imperfection like chemical composition and material defects.

(a) Uniform chemical composition: The chemical composition of the material will checked whether it is according to data given by company or not.

(b) Material defects: There may be some material defects on the blanking device which will be checked while investigation and these defects may be a failure reason.

4.Post Weld Heat Treatment:There may be some problem with the post weld heat treatment like cooling rate, Welding environment, and residual stress generation.

(a) Cooling rate: The cooling of the blanking device performed in open air cooling at $30^{\circ} \mathrm{C}$. The time taken is approx 30 minutes in investigation it will also checked.

(b) Environment: The welding environment is open air at $30^{\circ} \mathrm{C}$ at ground. Humidity is $70 \%$.

(c) Residual stress generation:The main reason of failure comes in brainstorming is residual stress generation.

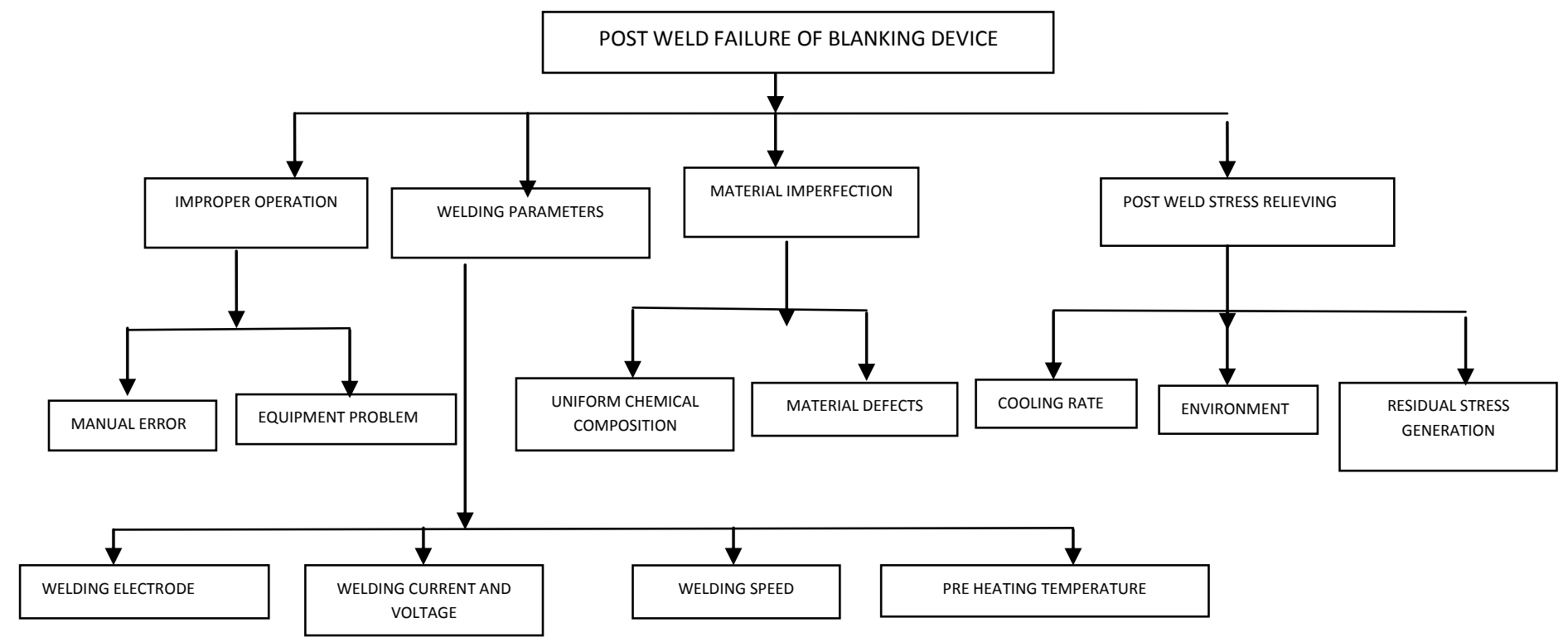




\section{PROPOSED METHODOLOGY}

Failure analysis is an investigation of failure mode and mechanism using optical, electrical,physical, and chemical analysis techniques. Before starting the analysis, it is necessary to collectdetails of the failure circumstances and symptoms. This includes investigation of variations in mechanical characteristics and other historical data leading to the failure, operating environment,stress conditions, mounting, and possibility of human errors. These factors may suggest thepotential failure mode and mechanism [5]. Based on this assumption, the most appropriate methodand procedure are determined. Insufficient information on the failure circumstances and symptomsmay lead to an unsuitable choice of analysis technique, consequently waste of valuable materialand time.

Visually inspecting the external condition of the device often provides valuable information forsubsequent analysis. First the device is inspected by eyes to check for any differences from goodones.Visual inspection is a nondestructive testing technique that provides a means of detecting and examining a variety of surface flaws, such ascorrosion, contamination, surface finish, and surface discontinuities on welds. Visual inspection is also the most widely used method for detecting and examining surface cracks.

Chemical analysis is needed to check the composition of the blanking plate at different places. It will give the information about whether the chemical changes happen or not and if happen then on which component and up to what amount. Chemical analysis will be performed by Optical electron spectrophotometer.

For detailed analysis of microstructure of material samples will be prepared as per the need. One sample is taken from outer part of blanking plate as it is considered as original part having no change due to welding and another one is taken from the heat affected zone as it had gone through all the changes.

Then microscopic inspections will carried out for detailed observation. A stereomicroscope with magnifying power 4 to 80 is used. Illumination from various angles is used to obtain the best view of the sample. A regular microscope with higher magnification power (50 to 2,000) is sometimes used to search for failure spots [7]. For further observation is required to detect packagecracks, surface wear, particles, whiskers, discoloration, or migration, a scanning electron microscope (SEM) is used.The scanning electron microscope (SEM) uses a focused beam of high-energy electrons to generate a variety of signals at the surface of solid specimens. The signals that derive from electron-sample interactions reveal information about the sample including external morphology (texture), chemical composition, and crystalline structure and orientation of materials making up the sample.Fractography will be performed by SEM (model JEOL JSM-6610) in the lab.

Micro hardness testing will performed to study the hardness of second phase particles.As it will give the information about the defect identification because every material defect has different hardness.

The simulation model will be generated on ANSYS to study the temperature distribution and distribution of thermal stress on the blanking plate using finite element analysis with aid of ANSYS software. This analysis will give the information about how much stress had developed in blanking plate at various radius and temperature. This will also help to find out what should be preheating temperature, cooling rate and heat input.

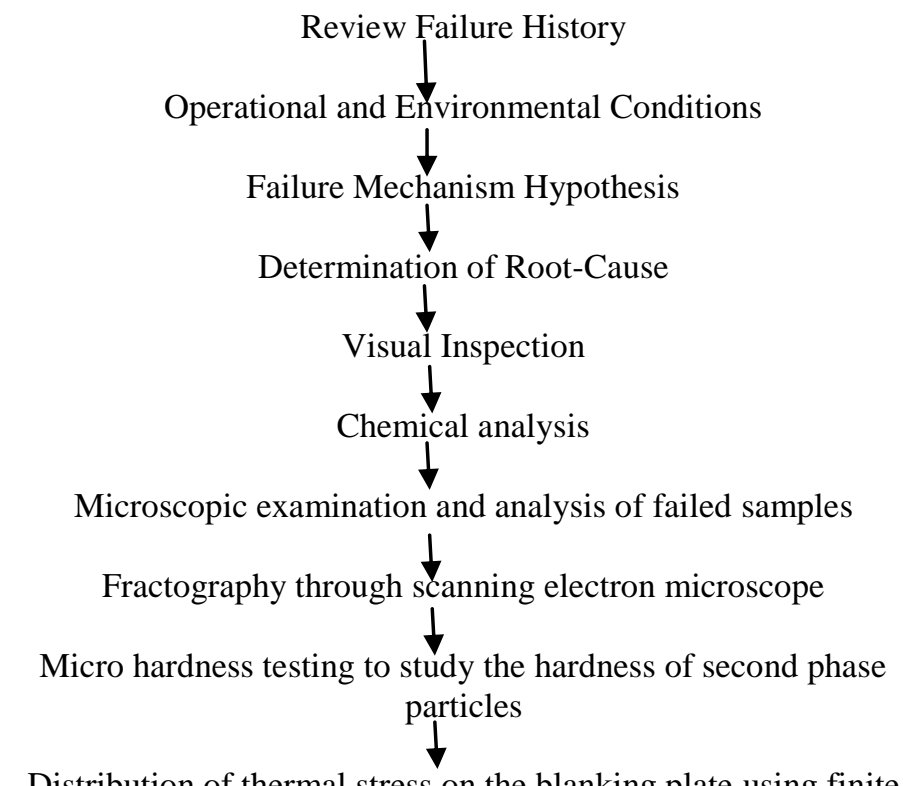

Distribution of thermal stress on the blanking plate using finite element analysis with aid of ANSYS software

(Flowchart of Failure Analysis)

\section{DISCUSSION}

From the above analysis of failure of blanking device it can be said that failure may happen due to one of the discussed reason or combination of two or more reasons which will clarify when investigation will performed. As it is found from brainstorming and investigation that there is no manual error and equipment problem. When leading to another failure causes like selection of welding parameters, material imperfection and post weld heat treatment may be reason of failure.

In selection of welding parameters it is found that electrode selection is correct and as per the requirement. Other parameters like welding current, welding voltage and welding speed need to check as it were correct or not. 
Material imperfection may be occurring due to non uniform chemical composition or due to any micro structural defect. Chemical analysis is also needed for material verification and micro structural analysis will cross check about quoted material properties.

Post weld heat treatment cameas main failure reason as failure happen during post weld heat treatment and there may be possibility of residual stress generation. The instantaneous residual stress on the weld surface may goes up to the yield strength of the material and this may beattributed as one of the significant reasons forthe development of cold cracks at the fusion zone in the high strength steel. Cooling rate also need to check and the environment is ok as welding on other blanking devices had successfully performed on same environment.

\section{CONCLUSIONS}

The failure reason of blanking device by brainstorming and fault tree analysis comes as material defect or generation of residual stress during post weld heat treatment. So now investigation is centered in micro structural analysis, chemical verification and residual stress calculation.

The micro structural analysis will performed by optical microscope and scanning electron microscope. The residual stress on the blanking plate will be analyzed by using finite element analysis with aid of ANSYS software.

\section{ACKNOWLEDGEMENTS}

The authors wish to thank Senior planning Engineer $\mathrm{Mr}$. Milan Sahu of Precision Engineering Components Govindpura Bhopal for his kind technical assistance throughout the failureinvestigation work.

\section{REFERENCES}

[1] Wulpi DJ. Understanding how components fail. 2nd ed. Materials Park, OH: ASM International; 1999.

[2] Becker WT, Shipley RJ, editors.ASM Handbook, Failure Analysis and Prevention.vol. 11. 10th ed., Materials Park, OH: ASM International; 2002.

[3] D. Aliya, The failure analysis process: an overview. In: Becker WT, Shipley RJ, editors. ASM handbook, failure analysis and prevention.vol. 11. 10th ed.Materials Park, $\mathrm{OH}$ : ASM International; 2002. p. 315-23.

[4] SeropeKlpakjian, Steven R. Schmid,Manufacturing Engineering and Technology, Pearson Education Asia, [2000].

[5] Ferjencik M. Root cause analysis of an old accident in an explosives production plant. Safe Sci 2010;48:1530-44.

[6] Le May I, Deckker E. Reducing the risk of failure by better training and education. Engng Fail Anal 2009;16:1153-62.

[7] McKinnon RC. Cause, effect, and control of accidental loss with accident investigation kit.CRC Press; 2000.
[8] Bhaumik S. A view on the general practice in engineering failure analysis. J Fail Anal Prevent 2009;9:185-92.

\section{BIOGRAPHIES:}

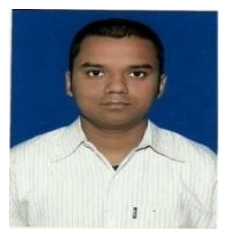

Sandeep Kumar,M.Tech in Maintenance Engineering \& Management, from Maulana Azad National Institute of Technology, Bhopal India, 